\title{
Community-level socioeconomic inequality in the incidence of ischemic heart disease: a nationwide cohort study
}

\author{
Jun Gyo Gwon ${ }^{1 \dagger}$, Jimi $\mathrm{Choi}^{2 \dagger}$ and Young Jin $\operatorname{Han}^{3^{*}} \mathrm{~B}$
}

\begin{abstract}
Background: The purpose of this study was to confirm that inequalities in community-level social economic status (SES) do actually impact the incidence of ischemic heart disease (IHD) using the Korean population-based cohort study of the National Health Insurance Service-National Sample Cohort (NHIS-NSC) database.

Methods: This study used the NHIS-NSC database, a population-based cohort database established by the NHIS in South Korea. Community-level SES was classified into three categories, i.e. low, moderate, and high, according to the rank. The outcome measure of interest was IHD, which was defined according to the International Classification of Disease, 10th Revision (ICD-10) codes.

Results: In the low community-level SES group, the incidence of IHD was 3.56 per 1000 person years (cumulative incidence rate, 1.78\%), and in the high community level SES group, it was 3.13 per 1000 person years (cumulative incidence rate, $1.57 \%$ ). Multivariate analysis showed that the incidence of IHD was higher in the low communitylevel SES group $(p=0.029)$. The log-rank test showed that the cumulative incidence of IHD was higher in the low community level SES group than the high community-level SES group (adjusted hazard ratio, 1.16; 95\% Cl, $1.01-$ 1.32).

Conclusions: People living in areas with low community-level SES show an increased incidence of IHD. Therefore, intervention in active, health-risk behavior corrections at the local level will be required to reduce the incidence of IHD.
\end{abstract}

Keywords: Epidemiology, Socioeconomic status, Ischemic heart disease, Health risk behaviors

\section{Background}

Ischemic heart disease (IHD) encompasses the diagnoses of angina pectoris, myocardial infarction, silent myocardial ischemia, and mortality that results from coronary artery disease [1]. Many studies have previously reported the association of IHD with individuallevel social economic status (SES). These studies have shown that the lower the individual SES, the higher the incidence of IHD [2-5]. Previous studies have reported that individual lack of awareness of both the risk factors for IHD and the health risk behaviors associated with IHD underlie these findings $[5,6]$. Local community

\footnotetext{
* Correspondence: medjin00@gmail.com

†Jun Gyo Gwon and Jimi Choi contributed equally to this work.

${ }^{3}$ Department of Vascular Surgery, Ulsan University College of Medicine and

Asan Medical Center, 88, Olympic-ro 43-gil, Songpa-gu, Seoul 05505, Korea

Full list of author information is available at the end of the article
}

influences this lack of awareness for risk factors for IHD and health risk behaviors associated with IHD, which include smoking, consumption of diets with high sodium and high content of trans-fats and low content of polyunsaturated fatty acids, consumption of sugarsweetened beverages, alcohol abuse, physical inactivity, and psychological stress [7-9]. However, to the best of our knowledge, no study has investigated whether differences in community-level SES affect the incidence of IHD. Therefore, the purpose of this study is to confirm that inequalities in community-level SES have an impact on the incidence of IHD through analysis of the Korean population-based cohort study of the National Health Insurance Service-National Sample Cohort (NHIS-NSC) database. 


\section{Methods}

\section{Study population}

This study used the NHIS-NSC database (NHIS2018-2-290), a population-based cohort database established by the NHIS in South Korea [10]. This is the national representative cohort database for health service use, in which approximately 1,025,340 patients $(2.2 \%$ of $46,605,433$ Korean residents in 2002) were followed up until 2013 by annually updating samples of newborn infants. From this database, all patients aged $\geq 20$ years in 2009 were identified. Patients without health check-up data or those with a history of ischemic heart disease before their enrollment were excluded (Fig. 1).

\section{Exposure measures}

Community-level SES of study subjects was defined as the local income for the residential area in which they lived in 2009. The gross regional domestic product (GRDP) per capita of 16 regions (seven metropolitan cities, including the Korean capital, and nine provinces) was used to measure the local income of subjects' residential area and ranked according to the GRDP [11]. Local income was then classified into three categories according to the ranking of GDPR per capita as low (ranks 12-16), moderate (9-11), and high (1-8) (Table 1). Each of the three categories contained a different number of regions as the total population was divided evenly into three categories.

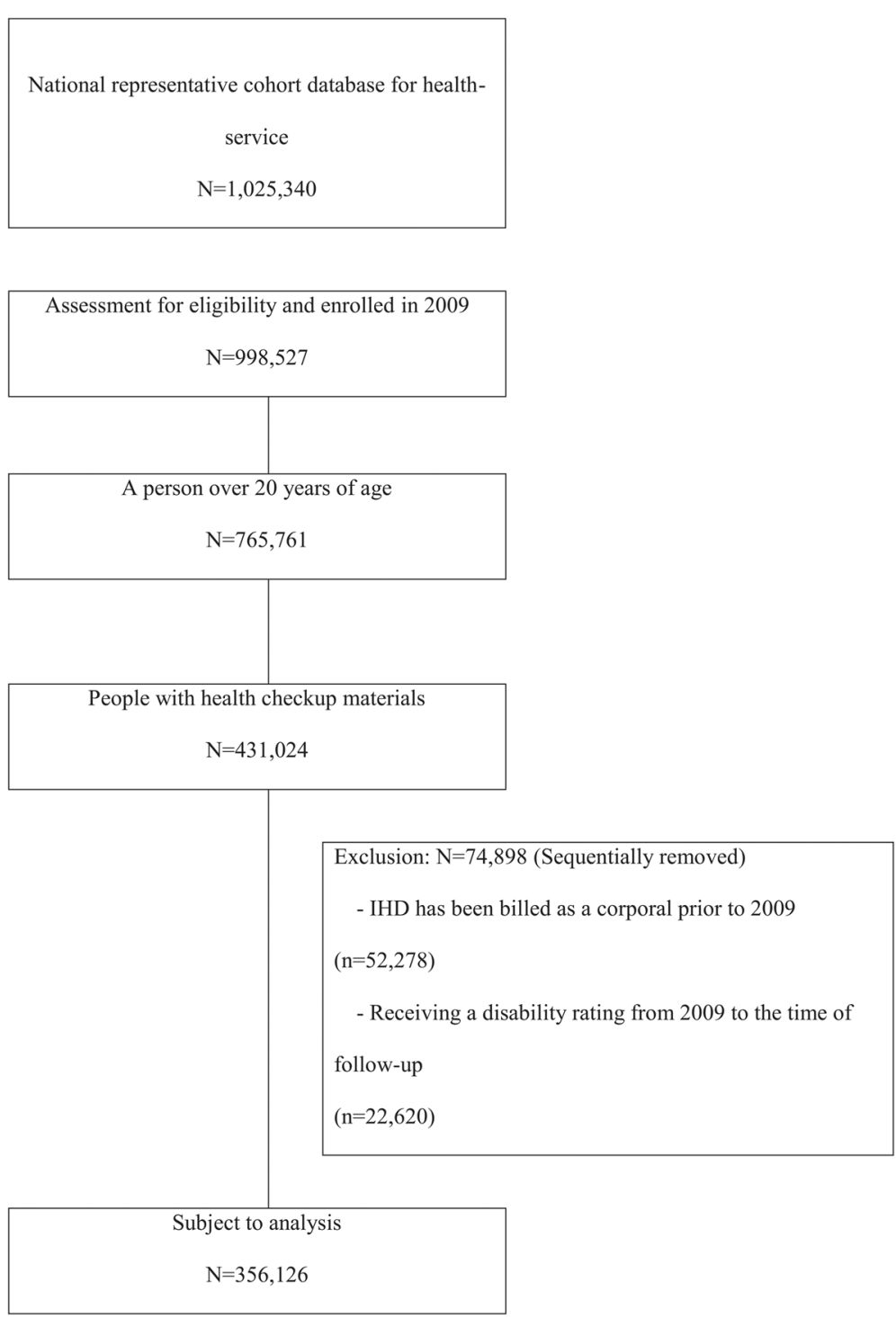

Fig. 1 Flowchart of the study 
Table 1 The gross regional domestic product per capita and Rank in 2009

\begin{tabular}{llll}
\hline District in South Korea & Regions & $\begin{array}{l}\text { Gross regional } \\
\text { domestic product } \\
\text { per capita in 2009 } \\
\text { (Unit: 10 KRW) }\end{array}$ & Rank \\
\hline Metropolitan city & Seoul (Capital) & 26.9 & 5 \\
& Busan & 17.4 & 13 \\
& Daegu & 14.5 & 16 \\
& Incheon & 19.9 & 9 \\
& Gwangju & 16.1 & 15 \\
& Daejeon & 16.9 & 14 \\
& Ulsan & 47.9 & 1 \\
& Gyeonggi & 20.8 & 8 \\
Gangwon & 19.6 & 10 \\
Province & Chungbuk & 23.0 & 7 \\
& Chungnam & 35.2 & 2 \\
& Jeonbuk & 19.4 & 11 \\
Jeonnam & 28.9 & 3 \\
Gyeongbuk & 27.7 & 4 \\
Gyeongnam & 26.1 & 6 \\
Jeju & 18.9 & 12 \\
\hline
\end{tabular}

\section{Outcome measures}

The outcome measure of interest was IHD, defined as according to the International Classification of Disease, 10th Revision (ICD-10) codes I20, I21, I22, I23, I24, and I25 [12]. Follow-up of all patients began on January 1, 2009, and ended when any of the following occurred: onset of ischemic heart disease, death from any cause, moving to a different region at baseline, and the end of the study period (December 31, 2013).

\section{Confounding variables}

Confounding variables evaluated included patients' age, sex, individual economic status, smoking status, body mass index (BMI) and the incidence of comorbidities including diabetes mellitus (DM), hypertension (HTN), dyslipidemia, peripheral arterial disease (PAD), and stroke at baseline. The people included in the NHIS are ranked into 21 categories on the NHIS-NSC database according to the insurance premiums that they pay. The NHIS calculates individual insurance premiums through consideration of income, assets, standard of living, and other economic factors. In our statistical modelling, individual economic status was evaluated as the average premium value for the insurance premiums in each ranks of NHIS. The history of disease was defined as follows: DM (ICD-10 E11, E12, E13, E14), HTN (I10, I11, I12, I13, I15), dyslipidemia (ICD-10 E78), PAD (ICD-10 I70.0, I70.2, I73.9, I70.8, I70.9, I74.2, I74.3, I74.4, I74.5), and stroke (ICD-10 I60, I61, I63).

\section{Statistical analyses}

Data are presented as means (standard deviation, SD) for continuous variables and as numbers (n) and percentages (\%) for categorical variables. Demographic and clinical characteristics among the regional income group were compared using the chi-square test or ANOVA, as appropriate. The incidence rate per 1000 person-years and cumulative incidence for IHD were calculated in each group. To evaluate the association between the risk of IHD and regional income level, Cox regression models with mixed effect ("Frailty model") were used. This model incorporates region-specific random effects to account for within-region homogeneity in outcomes [13]. Hazard ratios and 95\% confidence intervals were presented, and the high-income group was considered the reference group. Adjusted hazard ratios were obtained from the model including regions as random effect and age, sex, smoking, BMI, individual economic status, history of DM, HTN, dyslipidemia, PAD, and stroke as covariates. All statistical analyses were performed using SAS version 9.4 software (SAS Institute Inc., Cary, NC, USA), and a two-sided $P$-value $<0.05$ was considered statistically significant.

\section{Results}

\section{Baseline and clinical characteristics of the study} population

From January 2002 to December 2009, we identified a total of 356,126 patients, excluding those who had previously been diagnosed with IHD and those who were diagnosed according to a disorder code. Characteristics of the study population are shown in Table 2. Among the risk factors of IHD, the smoking ratio and BMI had higher prevalence rates $(p=0.006, p=0.001)$, whereas DM, HTN, and dyslipidemia had lower prevalence rates $(\mathrm{p}=0.006, p<0.001, \mathrm{p}<0.001)$ in the low communitylevel SES group. PAD had a higher prevalence rate with lower community-level SES $(p=0.044)$, whereas stroke was not associated with lower community-level SES ( $p=$ $0.745)$.

\section{Incidence of IHD according to the community-level SES}

In the low community-level SES group, the incidence of IHD was 3.56 per 1000 person years (cumulative incidence rate, $1.78 \%$ ), and in the high community-level SES group, it was 3.13 per 1000 person years (cumulative incidence rate, $1.57 \%$ ). Multivariate analysis showed that the incidence of IHD was higher in the low community-level SES group $(p=0.029$, Table 3$)$. Figure 2 shows the cumulative incidence of IHD according to the community-level SES cohort during the followup period using the Kaplan-Meier method. The logrank test showed that the cumulative incidence of IHD was higher in the low community level SES group than 
Table 2 Baseline characteristics of the study populations

\begin{tabular}{|c|c|c|c|c|c|c|}
\hline \multirow[t]{2}{*}{ Variables } & \multirow{2}{*}{$\begin{array}{l}\text { Total } \\
(N=356,126)\end{array}$} & \multicolumn{3}{|c|}{ Community level SES } & \multirow{2}{*}{$\begin{array}{l}p \\
\text { value }^{*}\end{array}$} & \multirow{2}{*}{$\begin{array}{l}p \text { for } \\
\text { trend }\end{array}$} \\
\hline & & $\begin{array}{l}\text { Low } \\
(N=109,632)\end{array}$ & $\begin{array}{l}\text { Medium } \\
(N=117,936)\end{array}$ & $\begin{array}{l}\text { High } \\
(N=128,558)\end{array}$ & & \\
\hline Age group, $\mathrm{n}(\%)$ & & & & & $<.001$ & 0.758 \\
\hline $20 \sim 29$ & $42,875(12.0)$ & $12,801(11.7)$ & $14,058(11.9)$ & $16,016(12.5)$ & & \\
\hline $30 \sim 39$ & $77,245(21.7)$ & $22,052(20.1)$ & $27,256(23.1)$ & $27,937(21.7)$ & & \\
\hline $40 \sim 49$ & $98,444(27.6)$ & $31,356(28.6)$ & $34,306(29.1)$ & $32,782(25.5)$ & & \\
\hline $50 \sim 59$ & $73,530(20.7)$ & $23,945(21.8)$ & $22,359(19.0)$ & $27,226(21.2)$ & & \\
\hline $60 \sim 69$ & $40,605(11.4)$ & $12,541(11.4)$ & $12,473(10.6)$ & $15,591(12.1)$ & & \\
\hline $70 \sim 79$ & $19,061(5.4)$ & $5635(5.1)$ & $6190(5.3)$ & $7236(5.6)$ & & \\
\hline $80 \sim$ & $4366(1.2)$ & $1302(1.2)$ & $1294(1.1)$ & $1770(1.4)$ & & \\
\hline Sex, n (\%) & & & & & $<.001$ & 0.135 \\
\hline Male & $180,598(50.7)$ & $54,738(49.9)$ & $61,160(51.9)$ & $64,700(50.3)$ & & \\
\hline Female & $175,528(49.3)$ & $54,894(50.1)$ & $56,776(48.1)$ & $63,858(49.7)$ & & \\
\hline Smoking Ever, n (\%) & $120,972(34.0)$ & $36,648(33.4)$ & $41,879(35.5)$ & $42,445(33.0)$ & $<.001$ & 0.006 \\
\hline Body mass index $\left(\mathrm{kg} / \mathrm{m}^{2}\right)$, mean (SD) & $23.4(3.2)$ & $23.4(3.2)$ & $23.4(3.3)$ & $23.3(3.2)$ & $<.001$ & 0.001 \\
\hline \multicolumn{7}{|l|}{ Co-morbidities } \\
\hline Diabetes mellitus, n (\%) & $28,745(8.1)$ & $8764(8.0)$ & $9321(7.9)$ & $10,660(8.3)$ & 0.001 & 0.006 \\
\hline Hypertension, n (\%) & $61,831(17.4)$ & $18,737(17.1)$ & $20,092(17.0)$ & $23,002(17.9)$ & $<.001$ & $<.001$ \\
\hline Dyslipidemia, n (\%) & $25,689(7.2)$ & $7745(7.1)$ & $8161(6.9)$ & $9783(7.6)$ & $<.001$ & $<.001$ \\
\hline Peripheral arterial disease, $\mathrm{n}(\%)$ & $5560(1.6)$ & $1829(1.7)$ & $1728(1.5)$ & $2003(1.6)$ & 0.001 & 0.044 \\
\hline Stroke, n (\%) & $6728(1.9)$ & $2098(1.9)$ & $2196(1.9)$ & $2434(1.9)$ & 0.658 & 0.745 \\
\hline $\begin{array}{l}\text { Individual economic status (Medical premium: won), } \\
\text { mean (SD) }\end{array}$ & $\begin{array}{l}77,526.1(56, \\
833.9)\end{array}$ & $\begin{array}{l}72,459.8(54 \\
259.6)\end{array}$ & $\begin{array}{l}78,492.6(56, \\
319.4)\end{array}$ & $\begin{array}{l}80,960.0(59 \\
100.8)\end{array}$ & $<.001$ & $<.001$ \\
\hline
\end{tabular}

* $p$-value by the chi-square test or ANOVA

in the high community level SES group (adjusted hazard ratio, 1.16; 95\% CI, 1.01-1.32). Figure 3 shows the risk of IHD associated with low community-level SES among the various subgroups according to demographic data and comorbidities. The significance of modification effects by each covariate regarding the risk of IHD associated with low community-level SES was also tested, and the results are shown as P for interactions. In the subgroup analysis conducted in the three groups according to individual economic status, individual economic status was shown to not affect the incidence of IHD according to community-level SES ( $p=$
0.084). Among the variables included in the subgroup analysis, only patients' age significantly modified the influence of low community-level SES on the risk of IHD $(p=0.019)$.

\section{Discussion}

\section{Community level SES and IHD}

The results of this study confirmed that even though the individual level of SES was adjusted, the incidence of IHD differed according to differences in the community level of SES. The lower the community-level SES, the higher was the incidence of IHD. We hypothesized

Table 3 Incidence rates of IHD according to the community level SES status

\begin{tabular}{|c|c|c|c|c|c|c|c|c|}
\hline $\begin{array}{l}\text { Community level } \\
\text { SES }\end{array}$ & Event & $\begin{array}{l}\text { Total person } \\
\text { years }\end{array}$ & $\begin{array}{l}\text { Incidence rate per } 1000 \text { person } \\
\text { years }\end{array}$ & $\begin{array}{l}\text { Cumulative Incidence }{ }^{a} \\
(\%)\end{array}$ & $\begin{array}{l}\text { Crude HR } \\
(95 \% \mathrm{Cl})\end{array}$ & $p$ & $\begin{array}{l}\text { Adjusted HR } \\
(95 \% \mathrm{Cl})\end{array}$ & $p$ \\
\hline Low & 1776 & $499,273.5$ & 3.56 & 1.78 & $\begin{array}{l}1.10(0.91- \\
1.33)\end{array}$ & 0.339 & $\begin{array}{l}1.16(1.01- \\
1.32)\end{array}$ & 0.030 \\
\hline Medium & 1513 & $531,663.9$ & 2.84 & 1.43 & $\begin{array}{l}0.97(0.76- \\
1.23)\end{array}$ & 0.768 & $\begin{array}{l}1.03(0.88- \\
1.22)\end{array}$ & 0.697 \\
\hline High & 1797 & $574,652.6$ & 3.13 & 1.57 & 1.00 & & 1.00 & \\
\hline$p$ for trend & & & & & 0.311 & & 0.029 & \\
\hline
\end{tabular}

${ }^{\mathrm{a}}$ By Kaplan-Meier's estimates

${ }^{\mathrm{b}}$ Adjusting by age, sex, smoking, body mass index, individual economic status, history of diabetes mellitus, hypertension, dyslipidemia, peripheral arterial disease, and stroke 


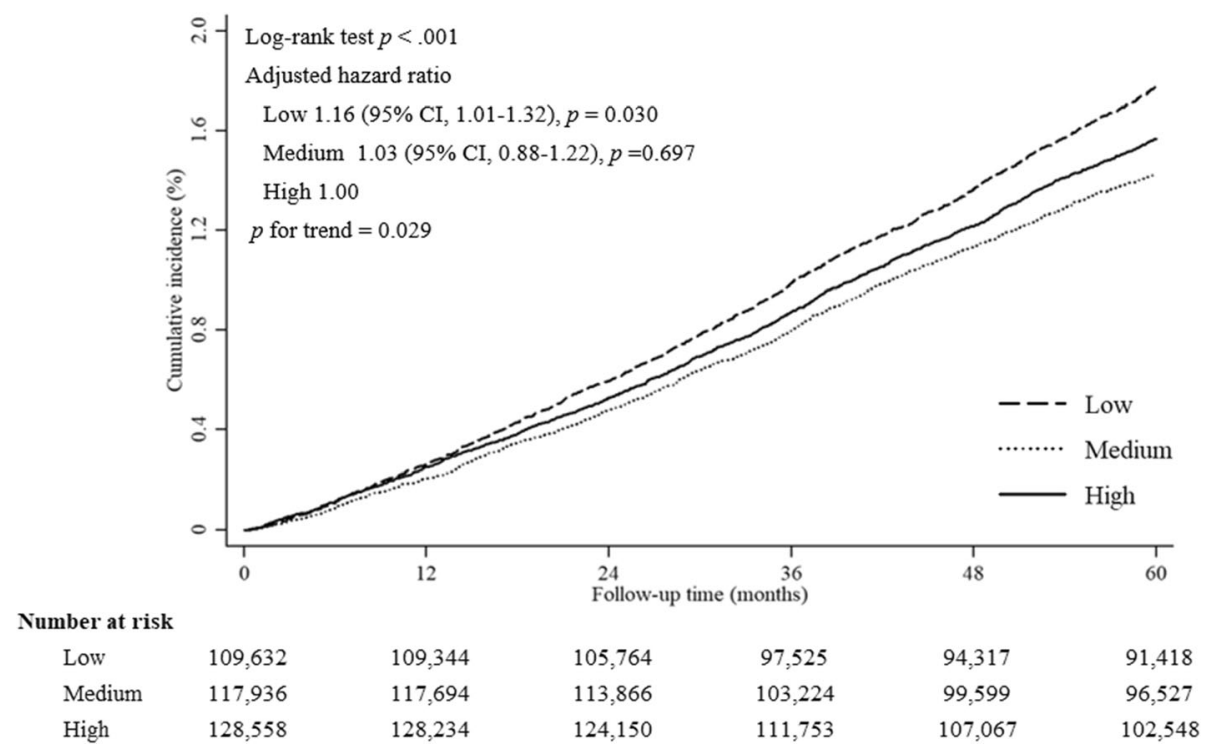

Fig. 2 Kaplan-Meier estimates showing the incidence of IHD in the three groups divided by community-level SES

that different health risk behaviors in different communities may have influenced the incidence of IHD, underlying these findings. Health risk behaviors, such as consumption of diets with high sodium and high levels of trans-fats, alcohol abuse, physical inactivity, and psychological stress all serve as risk factors for IHD and directly affect its incidence [7-9]. These health risk behaviors are influenced by neighbors, and the neighborhood environment is associated with communitylevel SES positions [14-19]. Mayen et al. reported that individuals consuming a healthier diet are also relatively less frequent in the low SES community [20]. Community-level people with high SES tend to share more information regarding health-related behaviors among neighbors or make an increased effort to reduce risk factors associated with IHD [21, 22]. Based on the results of this study, it is expected that the incidence of IHD will be lowered through community-level interventions such as promoting the use of educational materials on IHD or expanding smoking cessation areas. In fact, some studies have proposed that risk factors for non-communicable diseases, such as IHD, are more likely to be identified at lower SES levels and should, therefore, be controlled at the local level in order to reduce these risk factors $[23,24]$.

\section{Advantages of this study}

Previous SES-related studies have used income as a reference for SES [25-27]. However, as income does not reflect the level of real estate property, it is unlikely that it is an index that can accurately reflect personal assets. In this study, the government's medical insurance premium, which is proportional to tax, was used as an indicator of
SES. Tax reflects assets more objectively than does income because it also includes the value of owning real estate or an automobile. As this study is a nationwide, registerbased cohort study, a higher number of patients were included, along with the use of sample cohort data encompassing the entire nation, ensuring good quality data. Previous studies have mostly been conducted in developed countries with improved well-being $[4,25]$; therefore, participants included in those studies would have a relatively lower impact of SES on the medical outcome than most individuals worldwide. For example, in some European countries, where healthcare is provided free of charge, the difference in income will have less impact on the accessibility of health care services. In this respect, this study can more accurately report on the effects of SES inequality on medical outcomes than other studies pertaining to higher income countries. This is because the welfare benefits are relatively less developed and data are obtained from developing countries where SES is unfairly developed due to rapid urbanization [28]. Another advantage of this study is that there are no confounds due to medical differences between the races, as it was conducted in a single nationstate, unlike other nationwide cohort studies.

\section{Limitations of this study}

First, one of the indicators that reflects SES is the education level; however, there is no information regarding education level in this study. Despite this, stratifying patients' SES according to their educational background was not considered as meaningful, because more than $98 \%$ of patients included in this study had high school or higher education and more than $60 \%$ received a college education [29]. Second, the diagnosis of the disease may 


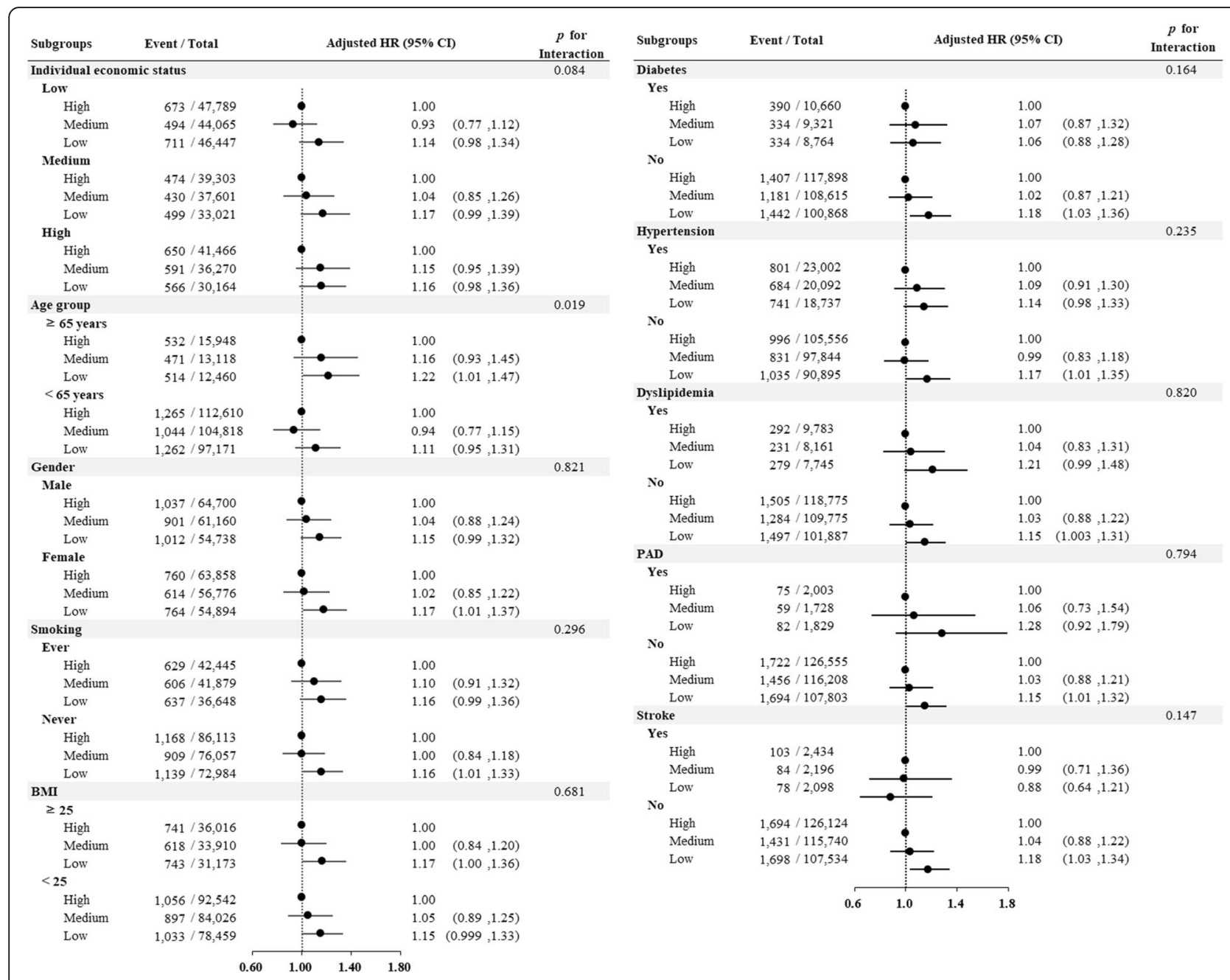

Fig. 3 Risk of IHD according to the community-level SES status in the subgroups stratified by other covariates

not be accurate. Data used in this study were based on physician's inputs of the disease, which was classified by ICD-10. Therefore, there is a lack of objective data as to why the physicians in-charge diagnosed the disease. A third limitation was that the results of this study were limited to aged subjects. In subgroup analysis, there was no difference in the incidence of IHD according to community level SES for those aged $<65$ years. Therefore, it is difficult to draw conclusions on the different incidence of IHD according to differences in community-level SES in people aged $<65$ years. However, because the incidence of IHD is relatively low in young age [30], people aged $<65$ years group may not have adequately reflected the incidence of IHD according to the difference of community level SES. In this study, there were also differences in the incidence of IHD between old age group and young age group. The incidence of IHD in people aged $\geq 65$ years was $4.56 \%$ (95\% CI, 4.34-4.80), and the incidence of IHD in people aged $<65$ years was $1.25 \%$ (95\% CI, 1.21-1.29).

\section{Conclusions}

People living in areas with low community-level SES tend to have an increased incidence of IHD. Therefore, interventions through active, health-risk behavior corrections at the local level should be implemented in order to reduce the incidence of IHD.

\section{Abbreviations}

BMI: Body mass index; DM: Diabetes mellitus; GRDP: The gross regional domestic product; HTN: Hypertension; ICD-10: International classification of disease, 10th revision; IHD: Ischemic heart disease; NHIS-NSC: National Health Insurance Service-National Sample Cohort; PAD: Peripheral arterial disease; SES: Socioeconomic status

\section{Acknowledgements}

Not Applicable.

\section{Authors' contributions}

YJH conceived of the study design. JGG wrote the manuscript. JMC analyzed the data. JGG and JC contributed equally to this work. The authors read and approved the final manuscript.

Funding

No funding was obtained for this study. 


\section{Availability of data and materials}

This data is available from the National Health Insurance Service-National Sample Cohort (NHIS-NSC) in Korea. However, NHIS (https://nhiss.nhis.or.kr) approval is required to use this data.

\section{Ethics approval and consent to participate}

This study was approved by the Institutional Review Board of Korea university hospital (IRB number: 2018AN0217). Permission to access National Health Insurance Service - National Sample Cohort data was granted by National Health Insurance Service chairman on 28th, September, 2018 (research management number: NHIS-2018-2-290). In order to ensure confidentiality in personal identification, the data used the in this study was organized in a way that assigns an identification number.

\section{Consent for publication}

Not applicable.

\section{Competing interests}

The authors declare that they have no competing interests.

\section{Author details}

'Department of Transplantation and Vascular Surgery, Korea University College of Medicine, Seoul, Korea. ${ }^{2}$ Department of Biostatistics, Korea University College of Medicine, Seoul, Korea. ${ }^{3}$ Department of Vascular Surgery, Ulsan University College of Medicine and Asan Medical Center, 88, Olympic-ro 43-gil, Songpa-gu, Seoul 05505, Korea.

Received: 13 September 2019 Accepted: 17 February 2020

Published online: 22 February 2020

\section{References}

1. Fihn SD, Blankenship JC, Alexander KP, Bittl JA, Byrne JG, Fletcher BJ, Fonarow GC, Lange RA, Levine GN, Maddox TM, et al. ACC/AHA/AATS/ PCNA/SCAI/STS focused update of the guideline for the diagnosis and management of patients with stable ischemic heart disease: a report of the American College of Cardiology/American Heart Association Task Force on Practice Guidelines, and the American Association for Thoracic Surgery, Preventive Cardiovascular Nurses Association, Society for Cardiovascular Angiography and Interventions, and Society of Thoracic Surgeons. Circulation. 2014;130(19):1749-67.

2. Agyemang C, van Oeffelen AA, Bots ML, Stronks K, Vaartjes I. Socioeconomic inequalities in acute myocardial infarction incidence in migrant groups: has the epidemic arrived? Analysis of nation-wide data. Heart. 2014;100(3):23946.

3. Kim NH, Kim TJ, Kim NH, Choi KM, Baik SH, Choi DS, Park Y, Kim SG. Relative and combined effects of socioeconomic status and diabetes on mortality: a nationwide cohort study. Medicine. 2016;95(30):-4403.

4. Ramsay SE, Morris RW, Whincup PH, Papacosta O, Rumley A, Lennon L, Lowe G, Wannamethee SG. Socioeconomic inequalities in coronary heart disease risk in older age: contribution of established and novel coronary risk factors. J Thromb Haemost. 2009;7(11):1779-86.

5. Tsuji M, Arima H, Ohkubo T, Nakamura K, Takezaki T, Sakata K, Okuda N, Nishi N, Kadota A, Okamura T, et al. Socioeconomic status and knowledge of cardiovascular risk factors: NIPPON DATA2010. J Epidemiol. 2018;28(Suppl 3):S46-52.

6. Fujino Y, Tanabe N, Honjo K, Suzuki S, Shirai K, Iso H, Tamakoshi A, Group JS. A prospective cohort study of neighborhood stress and ischemic heart disease in Japan: a multilevel analysis using the JACC study data. BMC Public Health. 2011;11:398.

7. Barquera S, Pedroza-Tobias A, Medina C, Hernandez-Barrera L, BibbinsDomingo K, Lozano R, Moran AE. Global overview of the epidemiology of atherosclerotic cardiovascular disease. Arch Med Res. 2015;46(5):328-38.

8. Wong JM, Na B, Regan MC, Whooley MA. Hostility, health behaviors, and risk of recurrent events in patients with stable coronary heart disease: findings from the heart and soul study. J Am Heart Assoc. 2013;2(5): e000052.

9. Auchincloss AH, Mujahid MS, Shen M, Michos ED, Whitt-Glover MC, Diez Roux AV. Neighborhood health-promoting resources and obesity risk (the multiethnic study of atherosclerosis). Obesity (Silver Spring). 2013;21 (3):621-8.
10. Lee J, Lee JS, Park SH, Shin SA, Kim K. Cohort profile: the National Health Insurance Service-National Sample Cohort (NHIS-NSC), South Korea. Int J Epidemiol. 2017;46(2):e15.

11. Korean National Statistitcal Office [http://kostat.go.kr/portal/korea/index.action]. Accessed 12 Nov 2018.

12. Barta A. ICD-10-CM official coding guidelines. J AHIMA. 2009;80(6):70-1.

13. Austin PC. A tutorial on multilevel survival analysis: methods, models and applications. Int Stat Rev. 2017;85(2):185-203.

14. Ross CE. Neighborhood disadvantage and adult depression. J Health Soc Behav. 2000;41(2):177-87.

15. Diez Roux AV, Mair C. Neighborhoods and health. Ann N Y Acad Sci. 2010; 1186:125-45.

16. Kawakami N, Winkleby M, Skog L, Szulkin R, Sundquist K. Differences in neighborhood accessibility to health-related resources: a nationwide comparison between deprived and affluent neighborhoods in Sweden. Health Place. 2011;17(1):132-9.

17. Yen $I H$, Michael $Y L$, Perdue L. Neighborhood environment in studies of health of older adults: a systematic review. Am J Prev Med. 2009;37(5):45563.

18. Won J, Lee C, Forjuoh SN, Ory MG. Neighborhood safety factors associated with older adults' health-related outcomes: a systematic literature review. Soc Sci Med. 2016:165:177-86.

19. Cooper RA, Cooper MA, McGinley EL, Fan X, Rosenthal JT. Poverty, wealth, and health care utilization: a geographic assessment. J Urban Health. 2012; 89(5):828-47.

20. Mayen AL, Marques-Vidal P, Paccaud F, Bovet P, Stringhini S. Socioeconomic determinants of dietary patterns in low- and middle-income countries: a systematic review. Am J Clin Nutr. 2014;100(6):1520-31.

21. Bjornstrom EE. An examination of the relationship between neighborhood income inequality, social resources, and obesity in Los Angeles county. Am $J$ Health Promot. 2011;26(2):109-15.

22. Davis SK, Winkleby MA, Farquhar JW. Increasing disparity in knowledge of cardiovascular-disease risk-factors and risk-reduction strategies by socioeconomic-status - implications for policy-makers. Am J Prev Med. 1995; 11(5):318-23.

23. Pullar J, Allen L, Townsend N, Williams J, Foster C, Roberts N, Rayner M, Mikkelsen B, Branca F, Wickramasinghe K. The impact of poverty reduction and development interventions on non-communicable diseases and their behavioural risk factors in low and lower-middle income countries: a systematic review. PLoS One. 2018;13(2):e0193378.

24. Allen L, Williams J, Townsend N, Mikkelsen B, Roberts N, Foster C, Wickramasinghe K. Socioeconomic status and non-communicable disease behavioural risk factors in low-income and lower-middle-income countries: a systematic review. Lancet Glob Health. 2017;5(3):e277-89.

25. Andersen KK, Dalton SO, Steding-Jessen M, Olsen TS. Socioeconomic position and survival after stroke in Denmark 2003 to 2012: nationwide hospital-based study. Stroke. 2014;45(12):3556-60.

26. Agyemang C, van Oeffelen AA, Norredam M, Kappelle L, Klijn CJ, Bots ML, Stronks $\mathrm{K}$, Vaartjes I. Socioeconomic inequalities in stroke incidence among migrant groups: analysis of nationwide data. Stroke. 2014;45(8):2397-403.

27. Pande RL, Creager MA. Socioeconomic inequality and peripheral artery disease prevalence in US adults. Circ Cardiovasc Qual Outcomes. 2014;7(4): 532-9.

28. Moore M, Gould P, Keary BS. Global urbanization and impact on health. Int J Hyg Envir Heal. 2003;206(4-5):269-78.

29. Gasior K. Education at a glance 2012: OECD indicators. Sociol Cas. 2013; 49(6):994-7.

30. Benjamin EJ, Muntner P, Alonso A, Bittencourt MS, Callaway CW, Carson AP, Chamberlain AM, Chang AR, Cheng S, Das SR, et al. Heart disease and stroke Statistics-2019 update: a report from the American Heart Association. Circulation. 2019;139(10):e56-e528.

\section{Publisher's Note}

Springer Nature remains neutral with regard to jurisdictional claims in published maps and institutional affiliations. 